\title{
"YO NO VALGO PARA ESTUDIAR...". UN ANÁLISIS CRÍTICO DE LA NARRACIÓN DE LAS EXPERIENCIAS DE EXCLUSIÓN SOCIAL
}

\author{
Teresa Susinos Rada \\ Adelina Calvo Salvador \\ Universidad de Cantabria
}

\begin{abstract}
"Lo seguro, en todo caso, es que nada es menos inocente que el laisserfaire: si es verdad que la mayoría de los mecanismos económicos y sociales que están en el origen de los sufrimientos más crueles, en especial los que regulan el mercado laboral y el mercado escolar, son difíciles de frenar o modificar, lo cierto es que toda política que no aproveche plenamente las posibilidades, por reducidas que sean, que se ofrecen a la acción, y que la ciencia puede ayudar a descubrir, puede considerarse culpable de no asistencia a una persona en peligro". (Bourdieu, Post-scriptum a La miseria del mundo, 1999)
\end{abstract}

RESUMEN: Este artículo revisa a partir de la narración de dos jóvenes (Luisa e Israel) cuáles son los principales hitos que ellos destacan en el proceso de exclusión escolar y social que se relata en su historia de vida. A través del uso de técnicas biográfico-narrativas tratamos de dar voz a los jóvenes y de reflexionar junto con ellos sobre cuáles son las barreras que la escuela y la sociedad imponen a algunos individuos y que finalmente les excluyen o discapacitan. Se exponen posteriormente los puntos de coincidencia en ambos casos, aquellos obstáculos que reconocen en su historia vital, y también los aspectos originales de cada narración, aquellos que hacen de la vida de Luisa e Israel una experiencia única. Por último, se exponen algunas reflexiones sobre cómo los discursos de los jóvenes matizan y amplían nuestro conocimiento sobre la exclusión social y ponen en cuestión a la escuela y a otras instituciones sociales.

ABSTRACT: This article reviews, from the narration of two young people (Luisa and Israel), which are the main landmarks that they emphasize in the process of social exclusion that is related in their history of life. Through the use of biographical-narrative techniques we try to give voice to the young people and to think together with them which are the barriers that the school and the society impose on some individuals and that finally exclude or disable them. 
The points of coincidence in both cases are exposed finally, those obstacles that both recognize in their vital history, and also the original aspects of each narration, those that make of the life of Luisa and Israel a unique experience. Finally, some reflections are exposed on how the discourses of the young people clarify and extend our knowledge about the social exclusion and put the school and other social institutions at issue.

PALABRAS CLAVE: exclusión social, investigación biográfico-narrativa, modelo social de discapacidad, subjetividad, experiencia.

KEYWORDS: social exclusion, biographical-narrative research, identity, experience.

\section{INTRODUCCIÓN: LA EXCLUSIÓN SOCIAL DESDE UNA PERSPECTIVA BIOGRÁFICO-NARRATIVA}

El presente artículo se enmarca en dos investigaciones que llevamos a cabo conjuntamente entre la Universidad de Cantabria y la Universidad de Sevilla ${ }^{1}$ (de las cuáles sólo la primera está ya concluida). En ambas investigaciones, por medio de diferentes técnicas biográfico-narrativas (Bolívar, 1999, 2001), pretendemos conocer cómo se ha ido construyendo la experiencia de la exclusión social para algunos chicos y chicas jóvenes. Intentamos con ello reconocer los hitos y problemas que ellos mismos identifican en su curso vital como elementos determinantes y que en su opinión podrían explicar las escasas oportunidades de participación social de las que actualmente disfrutan. Así pues, varios jóvenes, entre 18 y 25 años resumen en esta investigación las principales dificultades para la participación social que han experimentado.

Para describir esas dificultades y problemas en la vida social, nos hemos servido en nuestra investigación del concepto de barreras sociales (Zarb, 1997) en tanto que obstáculos que impiden a las personas la plena participación social y que finalmente les marginan y/o excluyen. En particular, hemos agrupado dichas barreras en cinco tipos: barreras personales, escolares, familiares, socio-comunitarias y laborales. Como veremos, nos centraremos en este artículo en analizar el primer tipo (barreras personales), tal y como son expresadas por los dos jóvenes que protagonizan esta investigación ${ }^{2}$.

Por otro lado, los colectivos en riesgo de exclusión social, tal y como han sido definidos tradicionalmente por la sociología (por motivos económicos, étnico-culturales y/o de género), se ven ampliados en nuestro trabajo con la consideración del

1. Parrilla, A. y Susinos, T. (dirs.) (2005) La construcción del proceso de exclusión social en mujeres jóvenes: origen, formas, consecuencias e implicaciones formativas. Informe de Investigación. Proyecto I+D financiado por el Instituto de la Mujer. Expte. 90/02 0000245 1010112003.

Parrilla, A. y Susinos, T. (dirs.) La construcción del proceso de exclusión social en jóvenes: Guía para la detección y evaluación de procesos de exclusión (Cantabria y Sevilla). I+D+I 2004-07 del Ministerio de Educación y Ciencia. Ref.: SEJ2004-06193-C02-02/EDUC. Investigación en curso.

2. En los siguientes artículos puede encontrarse mayor información sobre aspectos parciales de las investigaciones citadas: Susinos, T. y Parrilla, A. (2004); Susinos, T (2005); Calvo, A. y Susinos, T. (2005); Susinos, T., Rojas, S. y Haya, I. (2004); Lázaro S. y Palomera R. (2004); Gallego, C. y Hornillo, E. (2004); Hernández, E. (2004). 
colectivo de jóvenes con discapacidad. Nos adherimos de esta forma a los presupuestos del Modelo Social de la Discapacidad (Oliver, 1990; Barton, 1998 ; Barnes y Mercer, 1999), lo que nos permite mantener la hipótesis de que son las barreras sociales, los modos en que las instituciones y las estructuras sociales se organizan las que definitivamente excluyen o discapacitan a determinados grupos o personas y que en gran medida, estas barreras son compartidas por muchos de estos jóvenes, independientemente del grupo social al que pertenecen y al margen de sus características o déficits individuales.

La idea de la existencia de ciertos procesos y estructuras sociales que favorecen o dificultan la participación social de personas y colectivos, ha sido también subrayada por autores como Tezanos (2001a) o Castel (1997) al señalar que la exclusión social es un proceso (no una condición de las personas) que se va construyendo y que conlleva una pérdida del sentido de pertenencia para el individuo, así como la negación de determinados derechos y oportunidades económicos, sociales, políticos, culturales y/o educativos (Tezanos, 2001a).

En realidad, la exclusión podría entenderse también desde su concepto antagónico de ciudadanía social en el que igualmente encontramos un proceso interno o individual de desagregación y un proceso externo o social de fractura o marginación de determinados grupos o colectivos. Por ello, el término exclusión social es utilizado para referirse a "todas aquellas personas que, de alguna manera, se encuentran fuera de las oportunidades vitales que definen las conquistas de una ciudadanía social plena en los horizontes de finales del siglo XX" (Tezanos, 2001b: 138).

Por otro lado, son varios también los estudios sociológicos que han puesto de relieve que la existencia de estos procesos de exclusión social están generando una sociedad cada vez más polarizada donde la riqueza se va concentrando en un reducido número de personas a la vez que aumenta el número de pobres y los casos en los que esta pobreza se hace más extrema. Las desigualdades sociales están tomando formas que van más allá de la clásica desigualdad que tiene su origen en la clase social, sufriendo procesos de metamorfosis que se evidencian en nuevas formas de pobreza (por ejemplo las que viven las mujeres, los discapacitados, etc.) sostenidas o relacionadas con una progresiva retirada de las políticas estatales de lucha contra la exclusión y con una dificultad de las personas que sufren pobreza para identificarse y nombrarse como grupo (con algunas características comunes) lo que a su vez aumenta el grado de marginación y aislamiento de estos individuos (Torres López, 2001).

Así pues, para conocer cómo se experimentan, se mantienen y se producen los procesos de exclusión social, analizaremos aquí en detalle las historias de vida de dos jóvenes, Luisa e Israel, y en particular, aquello que hemos definido como barreras o impedimentos para la participación social. Más allá de la mera descripción de estas barreras, argumentaremos la importancia del significado y del sentido que los jóvenes atribuyen a las mismas y que puede ir desde lo más individual o íntimo hasta lo más social. Este análisis responde a la creencia de que la exclusión social es, ante todo, una experiencia y que ésta debe ser tenida en cuenta a la hora de explicar de forma global el fenómeno de la exclusión.

Finalmente, y en cuanto a la elección de los dos casos que conforman este artículo, la misma no se ha realizado bajo ningún tipo de criterio de representatividad, 
sino con la intención de otorgarle un valor individual a cada uno de los discursos como narraciones suficientes y con entidad propia, así como con la finalidad de analizar concurrencias y aspectos originales en cada una de ellas en relación a las barreras personales que se destacan en cada relato biográfico.

\section{El CONOCIMIENTO COMO DIÁlOGO ENTRE EL MUNDO DE LOS PARTICIPANTES Y EL DE LAS INVESTIGADORAS}

Tal y como hemos señalado, de todos los procesos y dinámicas que formarían parte de la exclusión social entendida ésta como algo en permanente construcción, nos centraremos en el análisis de las denominadas barreras personales que los dos jóvenes expresan en sus narraciones, entendiendo por tales aquellas declaraciones sobre "limitaciones o dificultades para la participación activa y en condiciones de igualdad en cualquier ámbito de la vida social que los jóvenes atribuyen a sí mismos -su etnia, cultura, género, origen social, religioso, capacidad y otras condiciones personales-" (Parrilla, A. y Susinos, T., 2005: 346). En la primera de las investigaciones que han inspirado este artículo, encontrábamos que era posible identificar en el discurso de los jóvenes afirmaciones que testimoniaban su claro convencimiento de que parte o muchos de sus fracasos para la participación social y escolar se explicaban (exclusivamente o preferentemente) desde sus propias limitaciones personales.

De esta forma, entendíamos que en nuestra investigación biográfico-narrativa era fundamental recoger la voz de los protagonistas, pero que esto no era suficiente. Es decir, que no debíamos centrar nuestros trabajos exclusivamente en transcribir literalmente el discurso de los jóvenes y evitar así cualquier influencia por parte de las investigadoras (puesto que entendemos que esto no es posible), sino que la percepción de los protagonistas sobre las cuestiones a investigar debía combinarse con la percepción de las investigadoras sobre estas mismas cuestiones (la cual, a su vez, no es única). Es lo que Sánchez Durá (1999) ha denominado la utilización de conceptos cercanos de la experiencia (en este caso los de los protagonistas del estudio) y conceptos distantes de la experiencia (los de las investigadoras) o lo que Díaz de Rada (2003) ha denominado la combinación del enfoque émic (interno al grupo o individuos que estudiamos) y étic (externo o ajeno al grupo o individuos que estudiamos) en la investigación. En ambos casos lo que se trata de establecer es que todo proceso de indagación, todo proceso de creación de conocimiento necesita del diálogo de estas dos perspectivas, del diálogo de los dos puntos de vista: el de los investigados y el de los investigadores. Es precisamente en esa conversación (en términos de Humberto Maturana) donde se genera conocimiento. Esquemáticamente nuestra propuesta sería la reflejada en la Fig. 1.

Dicho lo anterior, estamos en disposición de avanzar que, tal y como trataremos de argumentar a lo largo de este trabajo, en nuestra opinión las barreras personales que recogemos aquí son principalmente ejemplos de los procesos de naturalización de las barreras sociales. Es decir que, la existencia de estas barreras personales expresadas por ambos jóvenes demuestran cómo los mecanismos de psicologización y de atribución individual de las desigualdades sociales son enormemente potentes y eficaces en nuestras sociedades, hasta el punto de conseguir asentarse firmemente en los discursos y en las subjetividades de nuestros protagonistas. 


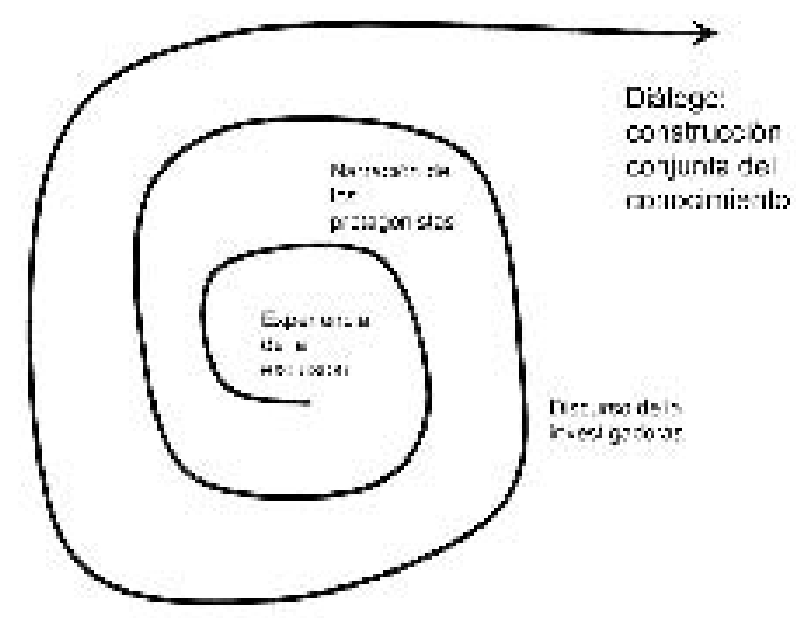

Fig. 1. Propuesta metodológica. El conocimiento como diálogo entre el mundo de los protagonistas y el de las investigadoras

\section{LA NATURALIZACIÓN DE LAS BARRERAS SOCIALES EN LOS DISCURSOS DE LOS PROTAGONISTAS}

A este procedimiento mental por el cual las barreras que impone la sociedad a algunos individuos (por ejemplo una institución social como es la escuela) son sustituidas en la argumentación de estas mismas personas por las barreras personales (por explicaciones basadas en los propios déficits o carencias) es a lo que se ha denominado proceso de naturalización o psicologización de los fenómenos sociales. Como veremos más adelante, este proceso relativamente frecuente en nuestras sociedades tiene un gran potencial para la construcción de un punto de vista conservador sobre el mundo y el ser humano.

En particular, los dos casos que presentamos a continuación no son igualmente representativos de estos discursos naturalizados y, como es previsible, mantienen algunos puntos de confluencia y otros que son originales en cada uno de ellos. Sin embargo, en una primera mirada, encontramos que globalmente consideradas, la narración de Luisa está mucho más limitada a las explicaciones de orden individual, sobre todo en lo que se refiere a la escuela. Es por así decirlo, un discurso mucho más impregnado de argumentos naturalizantes de la desigualdad, ya que, como veremos, abundan las denominadas barreras personales sobre las demás. Es posible que la discapacidad certificada de Luisa haya ejercido sobre ella una fuerte influen- 
cia en este sentido (lo que por otra parte, hemos podido comprobar en otras jóvenes con discapacidad entrevistadas), puesto que el discurso psicomédico, tan ampliamente extendido, se apoya justamente en las explicaciones basadas en el déficit individual y en la polaridad valorativa entre normalidad y anormalidad.

Por el contrario, es posible afirmar que el relato de Israel mantiene un equilibrio mayor entre las explicaciones de orden individual (barreras personales) y las de orden social (escolares, familiares, comunitarias, etc.). Es decir, para Israel no son sólo sus propias cualidades (déficits) las que explican sus dificultades sociales o escolares, sino que es capaz de esgrimir argumentos ajenos a sus propias limitaciones personales como elementos que han contribuido a conformar su situación actual.

Así pues, como veremos, Luisa encuentra casi sólo argumentos de índole individual para justificar su situación escolar. Es posible que su socialización como una mujer con discapacidad pueda tener relación con este tipo de discursos. Sin embargo, el discurso de Israel combina de forma más eficaz las barreras individuales y las sociales para explicar su participación social o su fracaso académico, por lo que se construye como un discurso con posibilidades de lanzar una mirada crítica a la estructura y a los procesos de participación social, pero también, como un discurso que trata de preservar su propia imagen personal.

Veamos a continuación algunos ejemplos de estas barreras sociales naturalizadas, tal y como son expresadas por los dos jóvenes. Para ello comenzaremos por presentar brevemente a los protagonistas de los discursos analizados, continuando después con una sucinta exposición de lo que han considerado las principales barreras para la participación a lo largo de su vida.

\section{LUISA}

\section{BREVE PERFIL BIOGRÁFICO}

Luisa tiene veinticuatro años. Trabaja en una fábrica ubicada en un polígono industrial a las afueras de Santander. Su puesto laboral en un Centro Especial de Empleo consiste en una tarea mecánica y repetitiva que se reduce a una parte muy concreta del proceso de fabricación de una conocida marca de galletas. Pese a tener una jornada laboral de nueve horas diarias y una experiencia en la empresa de tres años, su sueldo y el de su pareja, con el que comparte piso desde hace siete meses, no es suficiente para mantener el alquiler de una casa, por lo que son beneficiarios de una ayuda concedida por el ayuntamiento para alquiler de la vivienda.

Su experiencia escolar es recordada como una experiencia agradable en relación a su trato con el profesorado y con sus compañeros, pero con poco éxito, al no llegar a obtener el Graduado en Educación Secundaria. Pese a todo, Luisa ha participado en otros procesos formativos como un programa de garantía social o las diferentes actividades desarrolladas en el marco de la asociación de discapacitados a la que pertenece.

La pérdida de su madre, cuando ella contaba con seis años de edad, y el abandono por parte de su padre de las responsabilidades familiares, hicieron que Luisa y sus hermanos (cinco varones y una mujer) pasaran su infancia y adolescencia entre 
centros de protección de menores (habitualmente religiosos), colegios internos y los hogares de su tía y de su abuela materna.

Es precisamente este proceso de cambio en la unidad familiar lo que Luisa desearía no haber vivido y a lo que achaca buena parte de sus experiencias vitales más negativas o indeseadas.

\section{Y TÚ..., ¿ ¿ESTUDIAS O TRABAJAS?}

Cuando le preguntamos a Luisa sobre su experiencia en la educación reglada, sobre los distintos centros educativos por los que ha transcurrido su escolarización, y sobre la explicación de por qué, una vez obtenido el Graduado Escolar no siguió estudiando, Luisa contesta aclarando su deseo de finalizar cuanto antes la educación para poder trabajar: "yo solamente quería sacar el graduado escolar y después ya, pues, meterme a trabajar". En su caso, el estudio y el trabajo eran dos mundos totalmente diferenciados, incompatibles, y la formación, no se dibujaba como un instrumento de promoción social a través del desarrollo de un puesto laboral cualificado. Más bien al contrario: su prioridad no era hacer una "inversión" a largo plazo en la educación, sino obtener una mínima educación que le permitiera un acceso temprano al mundo laboral, pero no porque dicha formación fuera necesaria para el desempeño de un determinado puesto de trabajo sino porque era obligatoria. Vemos pues cómo Luisa mantiene un discurso dicotómico sobre el trabajo y el estudio, algo que desde el sistema educativo se sostiene y retroalimenta a través de la creación de itinerarios escolares (optativas, diversificaciones curriculares, programas específicos, etc.) que distribuyen a la población escolar proyectando así futuros diferentes que se traducen, en ocasiones, en el desempeño de empleos de diferente cualificación e importancia social y que en definitiva, ayudan a sostener las desigualdades sociales.

En realidad, cuando Luisa afirma que el mundo educativo y el laboral son incompatibles para ella, se está refiriendo en exclusiva a una educación vinculada a la escuela, puesto que ha recibido formación vinculada a puestos laborales concretos. De hecho, ella misma relata cómo las monjas (recordemos que Luisa se crió en Instituciones Residenciales) le buscaron varias salidas intentando que ocupara el tiempo que había entre la obtención del Graduado (a los 14 años) y la posibilidad de acceder al mundo laboral (a los 16 años, tal y como dicta la ley).

Sus primeras experiencias laborales (no remuneradas), sin embargo, no se dan hasta los 18-19 años, y están ligadas al estudio de un Programa de Garantía Social: "Auxiliar de ayuda a domicilio y residencias asistidas" que contemplaba la posibilidad de desarrollar un período de prácticas que Luisa completa en dos geriátricos. Posteriormente y con 20 años de edad, acude a un centro ocupacional gestionado por una asociación de discapacitados en el que desarrolla un curso de aproximadamente un año o año y medio. Su paso por este centro es la puerta de entrada al Centro Especial de Empleo en el que, tras un período de prueba (también sin remunerar), logra quedarse para trabajar en una cadena de fabricación de galletas. Este es el lugar en el que trabaja en la actualidad. 


\section{"Yo, en el COlegio, las liaba COMO AMANCiO"}

Cuando muere la madre de Luisa, su hermana y uno de sus hermanos (los de menor edad) se quedan en casa de su tía materna mientras que ella y el resto de sus hermanos (cuatro varones) son trasladados a sendas residencias regentadas por monjas. Los hermanos no pudieron permanecer juntos porque en estas residencias se mantenía una segregación por sexos. La residencia de Luisa no se encontraba ubicada en Santander lo que hizo aumentar todavía más la distancia (tanto física como psicológica) que separaba a ésta del resto de su familia. Esos primeros momentos son recordados como momentos difíciles en los que desarrolla un comportamiento inadecuado que le impedía una buena adaptación al contexto escolar. En el período de la educación primaria (su madre muere cuando ella contaba con seis años de edad), Luisa relata un episodio en el que, junto con otras compañeras de la residencia, se ve involucrada en una actividad que desencadenaría un castigo: hacer un fuego en el patio del centro.

"P. ¿Recuerdas el primer día de clase?

R. ¿El primer día de clase....? Fue muy malo, yo no quería ir. Con eso te lo digo todo (...), no me quería soltar de mi abuela y mi abuela me decía: "Luisa, que te tienes que quedar aquí, que te tienes que quedar"... Y yo no paraba de Ilorar, estuve berreando... hasta que poco a poco me fui haciendo al colegio, pero al principio, yo las liaba como Amancio.

P. ¿Cómo Amancio?

R. Sí, o sea, yo me acuerdo que en el colegio interno allí en Lopera, resulta que nos reunimos unas cuantas, ¿no?, en el patio, allí había pistas y al lado había columpios. Y resulta que cogimos unas revistas, las rompimos, luego cogimos un mechero, ique no sé de donde!, y queríamos hacer la hoguera de San Juan, y la hicimos. ¡Bueno que si la hicimos! ¡Después nos cayó un pedazo de bronca!! ¡Un castigo! Vino mi abuela al colegio y todo" (Entrevista Biográfica, [514-545]).

El relato que Luisa nos ofrece de este episodio se justifica, según ella comenta, por su inadecuado comportamiento en la escuela. Es ella quien, en primera persona, reconoce que su actitud no era la adecuada y en su discurso no hay otras fuentes que ayuden a comprender su conducta como por ejemplo, el sufrimiento que suponía el proceso de desestructuración familiar que estaba viviendo. Tampoco se hace referencia en modo alguno a las reglas o normas de los colegios o de las residencias en las que vivió Luisa, más bien al contrario, ella percibe y nombra siempre a su personal -en su mayoría religioso- como una ayuda para ella, en tanto que se esforzaron por crear en torno a Luisa el ambiente familiar del que ella carecía.

\section{"A mí NO SE ME QUEDAN LAS COSAS"}

En general, los recuerdos que Luisa tiene sobre su escolarización son buenos en cuanto al trato recibido por el profesorado, por el personal de las residencias, por sus compañeras y compañeros de la escuela, etc. Pero pese a estas ayudas por parte 
del personal docente, Luisa señala que siempre ha tenido problemas para poder estudiar, problemas que ella achaca a una meningitis que tuvo a edad muy temprana (al poco de nacer) y que hizo que su familia temiera por su vida más de una vez. Tal y como ella misma señala:

[sus compañeros de clase no se molestaban porque ella recibiera ayuda adicional del profesorado] "porque ellos decían, si a esta chavala la cuesta, pues habrá que echarla una mano, ¿no? (...) a mí que se me queden las cosas, es una dificultad enorme y eso ha sido todo a raíz de que tuve la meningitis, aunque no me acuerde de muchas cosas de cuando era pequeña (...)

P. ¿Dirías que esa época del colegio fue una época para ti fácil o difícil?

$R$. Difícil, porque no se me quedaban las lecciones, y eso.

P. ¿Qué cambiarías de esa etapa si pudieras volver atrás?

$R$. El no haber tenido la meningitis (...) las cosas hubieran sido mejores porque podría haber estudiado como cualquier niño, sin tener que tener ayuda" (Entrevista Biográfica, [806-825])

De esta forma, vemos en Luisa una atribución personal de las dificultades escolares que se traduce, en un primer momento, en entender su discapacidad como déficit individual, y en un segundo momento (como veremos a continuación), en una infravaloración de sus capacidades académicas. Esta atribución personal le hace percibirse a sí misma como una persona carente de capacidades, de ciertas habilidades, de memoria, etc. que le impedirían poder seguir el ritmo escolar que llevaban el resto de sus compañeros.

\section{"ME lO DIJE yo MiSMA: yo NO VAlgo PARA ESTUDiAR"}

La infravaloración de las capacidades, habilidades o saberes es la segunda forma que toma en Luisa la atribución personal de las dificultades escolares. Como ella misma señala, no hizo falta que nadie le dijera (ni un médico/a, ni un maestro/a, ni un familiar) que ella tenía dificultades para estudiar puesto que siempre tuvo muy claro los límites con los que contaba. Algo que, por otra parte, marcaría toda su vida, pues es dentro de esos límites donde ella ha encontrado trabajo (recordemos que trabaja en un Centro Especial de Empleo) y pareja (su novio también trabaja en un centro protegido de empleo).

A la pregunta de la investigadora, "¿cómo llegaste tú a la conclusión de que no servías para estudiar?, ¿recuerdas algún momento de tu vida en el que alguien te hizo saber esto?", Luisa señala:

$R$."No, no. No me lo dijo nadie, me lo dije yo misma. Me dije, yo no valgo para estudiar, yo no valgo para hacer una carrera. Las cosas no se me quedan (...) Para estudiar no valgo porque eso de sentarme y pegarme ahí los codos, no... no valgo. Yo soy muy hiperactiva, no puedo sentarme ahí cuatro horas leyendo. O sea, yo llego a casa, abro la cama, me cojo un libro y me lo leo, pero cuando estoy cansada paro. O sea que a mí no me dijo nadie "tú no vales para estudiar"" (Entrevista Focalizada, [1119-1131]). 
Además de una supuesta "insuficiencia" de capacidades, Luisa añade a su explicación ciertos rasgos de su personalidad que le han impedido mantenerse más tiempo en el sistema educativo: "soy muy hiperactiva". Ambos elementos forman parte del modelo más tradicional de explicación de la discapacidad (el Modelo Psicomédico) según el cual, las dificultades de participación social de las personas con discapacidad, ya sea en lo escolar, laboral, personal, etc. son siempre explicadas por las limitaciones que les impone su "déficit individual", lo que conlleva una ausencia de cuestionamiento de cualquier aspectos básico de la organización social.

\section{"Me gustaría tener otro lugar de trabajo"}

En tanto que razonamiento muy extendido en el imaginario colectivo, el Modelo Psicomédico está presente también en el discurso de Luisa. Un discurso que se ve plenamente reforzado a partir del proceso de certificación de una minusvalía que, como en el caso de nuestra protagonista, es con frecuencia la puerta de entrada al empleo precario. En concreto y para el trabajo de Luisa esto se traduce en: una jornada laboral de nueve horas con tres cuartos de hora para comer (actividad que también se desarrolla en la empresa) y un sueldo que no permite el pago del alquiler de una vivienda.

De hecho, a la pregunta de la investigadora "¿qué te haría más feliz en tu vida?", ella responde: "Que me tuvieran en cuenta para un trabajo fuera de ANCE [asociación de discapacitados]. Porque ha habido una chavaluca que le han encontrado un puesto en otra empresa. Así ganaría mucho más, conocería a otra gente y tendría otro lugar de trabajo" (Entrevista Biográfica, [1481-1504]).

En resumen, Luisa explica su situación actual debido a una discapacidad cuyo origen parece haber sido una enfermedad que padeció durante su infancia (meningitis). Es desde ahí desde donde ella comprende su dificultad para seguir el ritmo escolar (por cuestión de capacidad, comportamiento y personalidad) y lo que explica su deseo de abandonar cuanto antes la educación reglada para empezar a trabajar. Secundariamente encontramos otro centro en su relato a partir del cual narra su vida y que para ella supuso un incidente crítico: la muerte de su madre cuando ella contaba con seis años de edad.

Por otro lado, si bien en el ámbito escolar predominan de manera clara las atribuciones de sus dificultades a cuestiones relacionadas con sus "déficits", ocurre justo lo contrario en lo que al ámbito laboral se refiere. En este último aspecto, Luisa señala su deseo de cambiar de trabajo y subraya que las dificultades que diariamente encuentra en el despeño del mismo, tienen su origen en las condiciones laborales, que como ya hemos señalado, se desarrolla en el marco de un Centro Especial de Empleo.

Un resumen de las barreras personales y sociales que ha señalado Luisa sería el que refleja el siguiente cuadro. 


\begin{tabular}{|l|l|l|}
\cline { 2 - 3 } \multicolumn{1}{c|}{} & \multicolumn{2}{c|}{ Son entendidas como... } \\
\cline { 2 - 3 } \multicolumn{1}{l|}{ DIFICULTADES } & Barreras personales & "no se me quedan las cosas" \\
ACADÉMICAS & $\begin{array}{l}\text { "me costaba mucho estudiar } \\
\text { porque yo de pequeña tuve } \\
\text { meningitis" } \\
\text { "soy muy hiperactiva" } \\
\text { "en el colegio las liaba como } \\
\text { Amancio" } \\
\text { "no me gusta estudiar" } \\
\text { "yo no valgo para estudiar" } \\
\text { "en el colegio me veía mal porque } \\
\text { no estaba con mi familia" }\end{array}$ & \\
\hline DIFICULTADES & $\begin{array}{l}\text { "yo no quería entrar en ANCE } \\
\text { [asociación de discapacitados] } \\
\text { porque creía que allí sólo entraban } \\
\text { los chavales tontos" }\end{array}$ & $\begin{array}{l}\text { "mis compañeros son muy pesados" } \\
\text { "a veces la galleta viene mal en la } \\
\text { cinta } \\
\text { "los ingredientes de la galleta vienen } \\
\text { a granel y se pegan" } \\
\text { "me gustaría trabajar fuera de ANCE, } \\
\text { estar en una categoría más alta, } \\
\text { ganar más dinero y conocer a más } \\
\text { gente" }\end{array}$ \\
\hline
\end{tabular}

Cuadro 1. Resumen de las barreras señaladas por Luisa

\section{ISRAEL}

\section{BREVE PERFIL BIOGRÁFICO}

Israel es un joven de diecinueve años. Actualmente está cursando un Programa de Garantía Social de "Chapa y pintura de automóviles" después de haber pasado por la escolaridad obligatoria sin obtener el Graduado en Educación Secundaria. Los recuerdos sobre su trayectoria escolar son poco gratos. Tanto en los aspectos académicos como en sus relaciones sociales con compañeros, Israel relata experiencias que le sitúan entre la amargura y la indiferencia. No recuerda ningún amigo particular de su época de colegio, ni la atención más cercana de ninguno de sus profesores para ayudarle a mejorar en las tareas escolares que tanto le costaban. Se sentía, en sus propias palabras, como si él ocupara, a los ojos de los demás, una silla vacía. Ahora en "el Taller" es posible que Israel haya encontrado una primera experiencia de camaradería con sus compañeros y una afición por los coches que podría ser causa o efecto de su estancia en este Programa de Garantía Social.

En este momento vive con su padre, obrero no cualificado en una empresa cárnica, y su hermano, un año mayor que él. Su madre abandonó el hogar familiar poco tiempo después de nacer Israel. Su abuela es quien tangencialmente ha asumido las funciones maternas. Por lo demás, las relaciones con otros familiares son casi inexistentes a causa, opina él, del mal carácter de unos y otros. 
En su vida, destaca una queja fundamental que es sin duda el centro a partir del cual organiza su relato autobiográfico: su fuerte aislamiento social.

\section{"Tengo POCA Cabeza. Tampoco es QUe me gustara muChO estudiar"}

A partir de las palabras de Israel podemos conocer que tras su paso por la escuela primaria y secundaria no obtuvo ninguna titulación básica obligatoria. A pesar de su pertinaz "fracaso", este joven no peregrinó por diferentes colegios como es harto frecuente entre compañeros de similar rendimiento escolar. Por el contrario, permaneció siempre en el mismo centro, quizás debido a que "era un buen chico" y no planteaba problemas de conducta. Más bien al contrario, como él mismo expresa:

"mi hermano y yo, somos buenas personas, o sea, sitio que vamos, o sea somos muy... o sea, cómo decirle yo... o sea por ejemplo si vamos, no sé, si vamos por ahí por la calle pues somos buenas personas, no..., o sea que no nos ven como... que somos muy... cómo se dice la palabra, muy... muy inocentes vaya.

P. Inocentes.

R. O sea que... no nos metemos con nadie, o sea, que aguantamos mucho, si se meten con nosotros pues no... pues nosotros no somos gente que reacciona de mala manera ¿no? Nosotros hablamos, o sea, lo hablamos de buenas maneras, porque a mí no me gusta tener problemas ime entiendes?" (Entrevista Biográfica, [399-421]).

Esta misma idea se desarrollará más adelante al explicar cómo son sus relaciones sociales, pero de momento nos permite aquí defender la hipótesis de que pese a su pésimo rendimiento escolar, esto no le impidió continuar todo el tiempo matriculado en el mismo centro, en el que, sin embargo, nada muy diferente se le ofrecía año tras año. Ello fue posible, probablemente, porque la conducta de Israel no alteraba el ritmo ni el orden habitual de las cosas en el aula y en el centro.

En cualquier caso, los primeros argumentos de Israel para explicar sus dificultades escolares son explicaciones naturalizadas del rendimiento académico, es decir, sus propias limitaciones:"Y también no me siento orgulloso porque tengo poca cabeza. O sea, que me dicen una cosa y se me olvida al rato, de eso no, pues no me siento orgulloso" (Autopresentación, [87-98]). A este argumento añadirá más tarde otros igualmente psicologizados: se me olvidan las cosas, soy muy nervioso, no me gusta estudiar. En sus propias palabras:

"P. Y ¿por qué crees tú que eran malísimas (las notas)?

$R$. Yo creo que porque no... por eso que se me olvidaban, se me olvidaban muchas cosas, no sé y aparte de que yo era muy, muy nervioso y cuando ya no sé, los exámenes y todo eso pues, cuando te pones nervioso pues, no te acuerdas casi de nada.

P. Y eso ¿hay alguna otra... a lo mejor se te ocurre alguna otra causa de por qué eran malas?

R. Hombre, tampoco es que estudiara mucho, aparte de eso, tampoco es que me gustara mucho estudiar" (Entrevista Biográfica, [399-414]). 
Es decir, que en un primer momento las explicaciones que Israel encuentra a sus dificultades académicas son principalmente individuales (barreras personales). Sin embargo, y de forma paralela, Israel argumenta con vigor en contra de sus profesores y encuentra allí alguna explicación de su fracaso académico que ya no depende estrictamente de sus "déficits": los profesores le proponían tareas "que no valían para nada" y así, consecuentemente, ellos fueron responsables de no"cultivar su mente" cuando era pequeño. Literalmente su argumento se recoge en la entrevista como sigue:

P. Y normalmente ¿qué hacían (los profesores)?

$R$. Pues, pues no sé, me daban cosas para hacer pero no...

(...) Que como yo no hacía las mismas cosas que ellos pues no, pues eso que no, me daban cosas que no valían para nada, en una palabra.

$P$. Te daban cosas que no valían para nada.

R. Pues eso escribir cosas, pero, ellos también me echaban para un lado porque ellos me daban cosas, pues tonterías vamos.

$P$. Cosas fáciles dices.

$R$. Sí cosas fáciles, que no, que no, que no producían nada.

$P$. Que no te hacían pensar nada.

R. Eso nada.

P. Y normalmente, estabas siempre haciendo cosas distintas que los demás o no.

R. Siempre.

P. Siempre estabas haciendo cosas distintas.

R. Claro los profesores por eso... Yo creo que tenía poca cabeza por eso, porque al no estudiar, pues claro no... asimilaba las cosas poco.

P. Asimilabas poco.

R. Porque no era ni muy tonto ni muy listo, era por eso. Y claro, a medida que he ido creciendo pues la cabeza al no, pues no... cómo decirla, pues que no se ha cultivado va, que no, porque de pequeño si cultivas la mente, pues digo yo que de mayor seas más listo ¿no? Pero como no cultivaba la mente pues no, nada.

P. O sea que, tú crees que allí en el colegio no aprovechabas el tiempo.

R. Pues no. Pero es que nada (Entrevista Biográfica, [675-721])

Este mismo argumento crítico con sus profesoras aparece en otro momento más inicial de la entrevista, cuando asegura que las profesoras "me echaban para un lado" y que "para ellas era un estorbo tener a alguien así (...) que no sigue el ritmo de los demás"

Por tanto, podríamos adelantar que, pese a acudir a explicaciones basadas en su propia "incapacidad", en la narración de Israel asoma igualmente un cierto discurso crítico centrado en lo poco que la escuela hizo por él. Ciertamente estos argumentos son incipientes y se encuentran muy poco elaborados, puesto que Israel no es capaz de poner ejemplos o de detallar cómo podrían haberle ayudado más sus 
profesores ("haber puesto más atención en mí, que no me dejarían tanto de lado, que se habrían esforzado un poco en intentarme enseñar lo básico"), pero en cualquier caso deben ser tenidos en cuenta porque sin duda matizan su propia visión de sí mismo como estudiante. Sin embargo, no podemos decir que haya llegado a construir un discurso crítico sobre la escuela como institución, a la cual sigue considerando incontestablemente útil, por más que ello contradiga su propia experiencia.

\section{NO TENGO AMIGOS Y "SI NADIE TE HACE CASO TE DESMOTIVAS TOTALMENTE"}

Por otra parte, como ya hemos avanzado, para Israel la principal barrera para la participación que él experimenta en su vida es la ausencia de relaciones sociales. Prácticamente inicia su entrevista asegurando que "yo tengo muy pocos amigos. Pues sería muy importante para mí tener amigos, relacionarme con más gente" (Autopresentación, [35-38]).

Esta misma idea se va a repetir numerosas veces en su discurso, lo que nos lleva a pensar que sin duda dicha barrera sobresale sobre el resto. Pero, además, queda claramente enfatizada en sus palabras puesto que él se percibe como alguien "muy diferente a los demás", con una vida muy distinta:

"P. ¿Y en qué es tan distinta a la de los demás (tu vida)?

$R$. Pues no decir, pues por ejemplo ahora, ahora mismo, porque ellos tienen amigos, yo no tengo amigos.

P. ¿Y te gustaría tenerlos?

R. Pues sí, para salir por ahí, no tengo amigos ¿no?, y pues eso, que no tengo amigos, no tengo amigos" (Entrevista Biográfica, [875-883])

Ahora bien, es llamativo que, al igual que sucedió con las dificultades académicas, para Israel esta dificultad relacional se explica tanto por motivo de sus limitaciones personales (barreras personales) como por otras causas ajenas a sí mismo y que pueden ser atribuidas más bien a los demás.

En su discurso, podemos apreciar nítidamente esta combinación entre explicaciones internas y externas. Así, por ejemplo el siguiente párrafo combina ambos argumentos, sin que necesariamente el discurso resulte contradictorio:

"P. ¿Y por qué crees tú que no eras muy popular?

R. Pues yo que sé, porque era, porque era muy callado. Porque no me atrevía a hacer casi nada. Yo creo que era por eso, o sea, que era muy diferente a los demás. O sea porque ahora los chavales pues, pues no se callan por nada ¿no?, o sea que son más, o sea que yo soy diferente a ellos vamos. Que eso que son, que ellos son más sueltos, yo soy más... más calladito, o sea que no...

P. Y ¿por qué crees tú que eres así de callado?

$R$. Pues porque yo creo que siempre he sido así. O sea que desde pequeño hasta ahora no he cambiado, sigo siendo igual.

P. Y eso, ¿a qué se debe? 
R. Pues eso, pues que no... porque yo intento evitar los problemas que no, no me gusta tener problemas con nadie. Yo soy de estos chavales que son, que son muy sociables. Con, por ejemplo aquí, no me llevo casi bien con nadie porque con ellos no se puede hablar, con ellos no se puede hablar pero es que para nada.

\section{P. Pero ¿por qué?}

$R$. No sé... porque son, son mala gente. O sea que no... son, son muy raqueros $^{3 \prime}$ (Entrevista Biográfica, [575-608]).

Es interesante en este punto remarcar que en el discurso de Israel sobre el mundo de las relaciones sociales son más abundantes las explicaciones extrínsecas que las referidas a sus propias limitaciones. Así, encontramos numerosas expresiones con un contenido valorativo muy negativo hacia sus compañeros y estereotipos sociales sobre los jóvenes de su edad, amenazadores y/o despectivos. Este punto podría hacernos meditar largamente y sin duda nos llevaría a plantearnos numerosas hipótesis que son imposibles de resolver aquí: ¿por qué sus opiniones sobre sus compañeros son tan sombrías?, ¿por qué expresa estas visiones tan estereotipadas más propias de un entorno adulto?, ¿es posible que el mismo aislamiento social que Israel denuncia en su vida le lleve a mantener una visión de los jóvenes de estas características?, ¿por qué este aspecto pasó desapercibido durante toda su escolaridad?, etc.

Ciertamente, en sucesivas ocasiones asegura Israel haber intentado estrategias de acercamiento a sus compañeros ("hablar con ellos", "ser un poco como ellos", "jugar con ellos al fútbol, por ejemplo"), pero todas ellas resultaron sin éxito, hasta el punto que termina por compararse metafóricamente con una silla vacía ("es como si yo para ellos no estaría, es como un sitio libre de estos que ves ahí, por ejemplo, como aquí, si uno está aquí, y yo estoy aquí, es como si no estaría, como si está la silla vacía, pues así" (Entrevista Biográfica, [1103-1109]).

La idea de aislamiento social, obsesivamente repetida en su narración ("me quedaba más solo que la una"), es en su discurso causa última de casi todas sus dificultades y es capaz de explicar a sus ojos también su bajo rendimiento escolar: "yo iba muy disgustado al colegio, porque si nadie te hace caso, te desmotivas totalmente ¿no?, porque además te desmotivas y no estudias como tienes que estudiar, vas allí y vas sin ganas" (Entrevista Biográfica, [950-955]). Por tanto, la desazón de la soledad y el rechazo de los demás, son capaces de contaminar todo en su vida escolar y provocan, según Israel, la desmotivación que después afectará a todas las tareas escolares.

Veamos en el siguiente cuadro el resumen esquemático de cómo se combinan las explicaciones internas y externas en el discurso de Israel a la hora de explicar porqué su vida se ha visto limitada en la dimensión escolar y en la dimensión de las relaciones sociales.

3. "Raquero" es un localismo muy utilizado que actualmente significa quinqui, barriobajero, mal hablado. Los raqueros eran los chavales que vivían y callejeaban cerca de los muelles de Santander y se tiraban a la bahía a por monedas. 


\begin{tabular}{|c|c|c|}
\hline & \multicolumn{2}{|c|}{ Son entendidas como... } \\
\hline & Barreras personales & Barreras sociales \\
\hline $\begin{array}{l}\text { DIFICULTADES } \\
\text { ACADÉMICAS }\end{array}$ & $\begin{array}{l}\text { "tengo poca cabeza" } \\
\text { "se me olvidan las cosas" } \\
\text { "soy muy nervioso" } \\
\text { "no me gusta estudiar" }\end{array}$ & $\begin{array}{l}\text { "me daban cosas que no valían para nada, } \\
\text { cosas fáciles, cosas que no producían } \\
\text { nada" } \\
\text { "no cultivaron mi mente" } \\
\text { "es como si te verían (sic) un poco tonto" } \\
\text { "las profesoras me echaban para un lado" }\end{array}$ \\
\hline $\begin{array}{l}\text { DIFICULTADES } \\
\text { DE } \\
\text { INTERACCIÓN } \\
\text { SOCIAL }\end{array}$ & $\begin{array}{l}\text { "era muy callado" } \\
\text { "no me atrevía a hacer } \\
\text { casi nada" } \\
\text { "que ellos son más sueltos" }\end{array}$ & $\begin{array}{l}\text { "ahora los chavales no se callan por } \\
\text { nada" } \\
\text { "con ellos no se puede hablar pero es que } \\
\text { para nada" } \\
\text { "son mala gente. O sea que son muy } \\
\text { raqueros". } \\
\text { "yo veo que los chavales de ahora no te } \\
\text { respetan, te dejan tirado por ahi" } \\
\text { "te gastan bromas con mala idea" }\end{array}$ \\
\hline
\end{tabular}

Cuadro 2. Resumen de las barreras señaladas por Israel

Como vemos en el cuadro anterior, son principalmente dos las barreras personales que Israel reconoce en su vida. Una es preponderante sobre todo lo demás y se refiere a las dificultades que ha encontrado para entablar y mantener relaciones sociales con compañeros de clase o amigos fuera de la escuela. Es importante resaltar que esta dificultad es, para Israel, más importante y en cierto modo generadora de sus problemas escolares, que quedan en su discurso en un segundo plano. Igualmente, conviene recordar (como resumimos en el cuadro) que ambas barreras, académica y social, tienen en el discurso de Israel una explicación que no está completamente naturalizada y que por tanto no se explica sólo desde factores internos o psicologizados, sino también desde las dificultades que le impone el entorno y "los otros". Esta combinación entre las explicaciones naturalizadas y las explicaciones atribuidas a las imposiciones del entorno dan lugar a un discurso más equilibrado y como señalábamos anteriormente, más posibilitado para mantener una visión más crítica de la sociedad.

\section{Conclusiones. Para seguir indagando}

El sentido que Luisa e Israel dan a las dificultades que encuentran y que han encontrado para participar en la sociedad en la que viven, tiene una importancia vital para construir un determinado punto de vista sobre el mundo y sobre ellos mismos. Tal y como hemos querido señalar con esta investigación, nos encontramos ante dos jóvenes que, al atribuir las dificultades de participación social a sus hándicaps, a lo que hemos denominado barreras personales, lanzan una mirada a la sociedad como un sistema con poca o ninguna necesidad de cambio. $Y$ en relación a este discurso sobre el mundo, tienen una concepción de sí mismos como 
sujetos con una problemática individual que les ha incapacitado para Ilevar el tipo de vida que desean, una vida que no les separe de los demás, que no los haga tan diferentes a ellos.

Con respecto a este inmovilismo social, nos ha parecido particularmente importante la definición que ambos hacen de la escuela como un lugar donde se desarrollan aprendizajes relevantes que permiten a las personas situarse en una buena posición social. Es decir que, aunque sus propias experiencias escolares parezcan indicar lo contrario, estos jóvenes mantienen intacto el discurso dominante de la escuela como lugar neutro e inocente del saber, como institución válida para la promoción social de todos los individuos y como espacio que genera y alimenta aprendizajes relevantes. En palabras de Israel "estudiar en la escuela sirve para tener un futuro mejor". De ello se deduce que, quien no llegue a vivir la escuela de esta forma, se convierte en una persona con una problemática individual cuyo origen y causa se localiza en sus propios déficits individuales.

¿Cómo ha podido la escuela generar grupos o personas excluidas y, al mismo tiempo, evitar que estas mismas reconozcan los mecanismos y estructuras de la organización escolar que ayudan en esta tarea? Quizás, como ya señalaran Varela y Álvarez-Uría (1991), la escuela de hoy en día, como escuela heredera de la Contrarreforma ha logrado erigirse como un espacio neutral, sagrado, fuera de toda crítica en tanto que los conocimientos con los que allí se trabajan son conocimientos totalmente descontextualizados, ajenos a cualquier problemática o necesidad social, fuera de toda crítica o contestación. En definitiva, la escuela ayuda a conformar una visión neutra de las organizaciones y procesos sociales, incluida la propia escuela.

En segundo lugar, no sólo la institución escolar ayuda a ese proceso de naturalización de los procesos sociales que hemos analizado repasando las historias de vida de Israel y de Luisa. Puede que la investigación educativa también haya contribuido a esta finalidad, sobre todo aquel tipo de investigación que ha sido hegemónica durante mucho tiempo en las ciencias sociales y que ha tomado como principal metodología de trabajo el método hipotético-deductivo, una forma de trabajo derivada de las "ciencias naturales". Su poder para naturalizar los procesos sociales se pone en marcha al establecer explicaciones totales, unidireccionales y simplificadas de la realidad que tratan de imponerse como la visión más científica al negar el punto de vista desde el que estas visiones han sido creadas.

Por ello, la investigación que aquí se presenta entiende que la creación de conocimiento es siempre un diálogo entre diferentes puntos de vista y que precisamente ha sido uno de ellos, el de los sujetos investigados, el que tradicionalmente se ha silenciado. Es necesario por tanto seguir indagando en cómo dar la voz a los protagonistas de nuestros estudios y para ello servirnos de estrategias o instrumentos que les permitan expresar con facilidad su propia experiencia y puntos de vista. Aquí nos hemos basado en algunos instrumentos que como la entrevista biográfica, la autopresentación o la entrevista focalizada, han caracterizado nuestro enfoque biográfico-narrativo. En este sentido compartimos con Plummer (2005) la necesidad de aproximar nuestras metodologías a las que tradicionalmente han sido propias de las humanidades, porque recogen de forma más fidedigna la experiencia individual 
convirtiendo de este modo a las personas en agentes sociales, en sujetos de su propia vida. Por otra parte, ésta ha sido también una fuerte reivindicación del Movimiento de Discapacidad quienes, desde lo que se viene denominando Investigación Emancipatoria (Barton, 2005), reclaman un mayor protagonismo en los estudios que sobre ellos se realizan.

En este sentido, entendemos que la exclusión social es, ante todo, una experiencia, que debe ser no sólo vivida sino también narrada por sus protagonistas porque, tal y como han señalado Connell y Clandinin (1995), en toda narración existe no sólo un "cómo son las cosas" sino también un "cómo podrían ser o haber sido de otra manera", lo que abriría algunas vías para el cambio personal y social.

En tercer lugar y relacionado con lo anterior, tanto Luisa como Israel han descrito cuestiones de su vida que les impiden un acceso pleno a la ciudadanía social, algunas de ellas ampliamente señaladas en la literatura sociológica sobre el tema de la exclusión social. Así por ejemplo, la ausencia de red social (en el caso de Israel) o la vivencia, en el caso de Luisa, de lo que Laparra, Gaviria y Aguilar (1998) han denominado un "empleo de exclusión" (caracterizado por aspectos como la eventualidad, las malas condiciones de trabajo, los bajos salarios, el acceso a las pensiones más bajas de la Seguridad Social) pueden ser considerados como indicadores "fuertes" de exclusión social. De igual modo, ambos casos tienen en común, una trayectoria escolar vivida "al margen", Ilena de insatisfacciones y de fracasos, lo que se ha traducido en que ninguno de los dos haya logrado el Graduado en Educación Secundaria y en que ambos hayan cursado un Programa de Garantía Social. Les une también una vida familiar con ausencia de la figura materna. Por último, tal y como hemos tratado de mostrar, el discurso de Luisa parece responder a lo que hemos denominado una mayor "psicologización de los problemas sociales", más que el de Israel, lo que podría ser debido a la eficacia de los procesos de etiquetado formales (minusvalía) e informales que ha vivido. Ello ha favorecido el afianzamiento de un discurso y de una subjetividad de "mujer discapacitada". Sin embargo, y aunque en el caso de Israel no existe un procedimiento formal de etiquetación, los mecanismos informales de señalamiento que se producen en la escuela tanto por parte de sus profesores como de sus compañeros, tienen sin duda efectos similares de "discapacitación".

En cualquier caso, no queremos terminar sin reconocer que, aunque existen sin duda muchos aspectos en común en la narración de Luisa y de Israel que les hacen protagonizar desde lugares y perspectivas diferentes el fenómeno de la exclusión social, también es cierto que cada uno de ellos presenta sus propias particularidades. Y esto significa que algunas de las experiencias que han vivido nuestros protagonistas no son iguales, como tampoco lo son el relato que hacen de las mismas, ni los significados que les atribuyen, porque, en definitiva, cada vida es única. Si estamos de acuerdo con estas premisas, parece una tarea urgente de la investigación social respetar esas diferencias y abrir un diálogo con ellas desde el que proyectar un mundo más justo. 


\section{Bibliografía}

BARNES, C., et al. (1999): Exploring disability: a sociological introduction. Polity Press: Cambridge.

BARTON, L. (comp.) (1998): Discapacidad y sociedad. Madrid: Morata.

- (2005): "Emancipatory research and disabled people: some observations and questions". Educational Review, 57, 3, 317-327.

BOLÍVAR, A. (1996): Ciclo de vida profesional del profesorado de secundaria. Desarrollo personal y formación. Bilbao: Mensajero.

BOLÍVAR, A. et. al. (2001): La investigación biográfico-narrativa en educación. Madrid: La Muralla.

BOURDIEU, P.(1999): La miseria del mundo. Madrid: Akal.

CALVO, A. y SUSINOS, T. (en prensa): "Ausencias y presencias femeninas. Estudio de la exclusión social y la construcción de la subjetividad femenina en mujeres jóvenes a través de metodología biográfico-narrativa". En M. García Lastra (coord.): XI Conferencia de Sociología de la Educación. Septiembre de 2005. Santander

CASTEL, R. (1997) La metamorfosis de la cuestión social. Una crónica del salariado. Buenos Aires: Paidós.

CONNELLY, F. M y CLANDININ, D. J (1995): "Relatos de experiencia e investigación narrativa". En J. Larrosa et.al.: Déjame que te cuente. Ensayos sobre narrativa y educación. Barcelona: Laertes, 11-51.

DÍAZ DE RADA, A. (2003): Etnografía y técnicas de investigación antropológica. Madrid: UNED.

GALLEGO, C. y HORNILLO, E. (2004): "La trasgresión como vía de escape a la exclusión social: la historia de vida de Javier". En J. López et al. (eds.): Cambiar con la sociedad, cambiar la sociedad. Actas $8^{\circ}$ Congreso de Organización de Instituciones Educativas. Sevilla: Universidad de Sevilla, 315-316.

HERNÁNDEZ, E. (2004) "Análisis de los indicadores de exclusión e inclusión educativa concurrentes en la trayectoria escolar de jóvenes en situación de riesgo". En J. López et. al. (eds.): Cambiar con la sociedad, cambiar la sociedad. Actas $8^{\circ}$ Congreso de Organización de Instituciones Educativas. Sevilla: Universidad de Sevilla, 317-326.

LAPARRA, M., GAVIRIA, M. y AGUILAR, M. (1998): "Aproximaciones a la exclusión social". En J. Hernández Aristu y M. Olza Zubiri (comp.): La exclusión social: reflexión y acción desde el trabajo social. Navarra: Eunate, 19-50.

LÁZARO, S. y PALOMERA, R. (2004): "Identificación de factores protectores frente a la exclusión social y escolar en jóvenes en situación de desigualdad. Aproximación desde un enfoque biográfico-narrativo". Actas del IV Congreso Internacional de Psicología y Educación. Calidad Educativa. Almería: publicación electrónica, 2815-2823.

MATURANA, H. (1995): La realidad: ¿objetiva o construida? Barcelona: Anthropos. OLIVER, M. (1990):The politics of disablement. London: McMillan.

PARRILLA, A. y SUSINOS, T. (dirs.)(2005): La construcción del proceso de exclusión social en las mujeres: origen, formas, consecuencias e implicaciones formativas. Memoria del Proyecto financiado por el Instituto de la Mujer. Disponible en: www.mtas.es/mujer/mujeres/estud_inves/666.pdf. 
PLUMMER, K. (2005) Documents of life. London: Sage Pub.

SÁNCHEZ DURÁ, N.(1999): "Introducción". En C. Geertz: Los usos de la diversidad. Barcelona: Piados/ ICE-UAB, 9-35.

SUSINOS, T. (2005): "The construction of social exclusion process in young people: a biographical-narrative approach". Actas Congreso ISEC. Inclusion: celebrating Diversity?. Glasgow.

SUSINOS, T. y PARRILLA, A. (2004) "Barreras para la inclusión educativa y social. Experiencias sobre la vida en la escuela y la comunidad narradas en primera persona". En J. López et al. (eds.): Cambiar con la sociedad, cambiar la sociedad. Actas $8^{\circ}$ Congreso de Organización de Instituciones Educativas. Sevilla: Universidad de Sevilla, 309-312.

SUSINOS, T., ROJAS, S. y HAYA, I. (2004): "Barreras para la participación desde un enfoque biográfico-narrativo. "Dar la voz" en situaciones de máxima dificultad comunicativa". En R. E. Valley y E. J. Díez: Educación y diversidad: comunidades educativas. Actas del Congreso Internacional. León: Universidad de León, 1-15.

TORRES LÓPEZ, J. (2001): "Políticas económicas, pobreza y desigualdad". En J. F. Tezanos (ed.) (2001a): Tendencias en desigualdad y exclusión social. Madrid: Sistema, 79-104.

TEZANOS, J. F. (ed.) (2001a): Tendencias en desigualdad y exclusión social. Madrid: Sistema.

- (2001b): La sociedad dividida. Madrid: Biblioteca Nueva.

VARELA, J. y ÁLVAREZ-URÍA, F. (1991): Arqueología de la escuela. Madrid: La Piqueta.

ZARB, G. (1997) "Researching disabling barriers". En C. Barnes y G. Mercer: Doing disability research. Leeds: The disability press, 49-66. 